\title{
Erratum to: Behavioural and Electrophysiological Responses of Mosquito Vectors Aedes aegypti, Anopheles stephensi and Culex quinquefasciatus to an Ethyl Ester: Ethyl 2-Aminobenzoate
}

\author{
Johirul Islam ${ }^{1,2}$ - Sunil Dhiman ${ }^{3}$ - Varun Tyagi ${ }^{3}$. \\ Sanjukta Duarah ${ }^{1}$ - Kamaruz Zaman ${ }^{2}$. \\ Pronobesh Chattopadhyay ${ }^{1}$
}

Published online: 21 July 2017

(C) Springer Science+Business Media, LLC 2017

\section{Erratum to: J Insect Behav \\ DOI 10.1007/s10905-017-9614-4}

The original version of this article unfortunately contained errors. In the proof pdf version of the article all the "greater than symbols" as well as "less than symbols" especially in Tables 1 and 2 were missing as these characters were unconverted during typesetting.

With these errors, this correction note is hereby published to make those characters be visible on the article proof.

The original article was corrected.

The online version of the original article can be found at http://dx.doi.org/10.1007/s10905-017-9614-4

Johirul Islam

johirulmon@gmail.com

1 Division of Pharmaceutical Technology, Defence Research Laboratory, Tezpur, Assam 784001, India

2 Department of Pharmaceutical Sciences, Dibrugarh University, Dibrugarh, Assam 786004, India

3 Division of Medical Entomology, Defence Research Laboratory, Tezpur, Assam 784001, India 